\title{
Talaromyces minioluteus: New Postharvest Fungal Pathogen in Serbia
}

\author{
Stefan Stošić, ${ }^{1, \dagger}$ Danijela Ristić, ${ }^{1}$ Katarina Gašić, ${ }^{1}$ Mira Starović, ${ }^{1}$ Milica Ljaljević Grbić, ${ }^{2}$ Jelena Vukojević, ${ }^{2}$ and Svetlana Živkovićc \\ ${ }^{1}$ Department of Plant Diseases, Institute for Plant Protection and Environment, 11000 Belgrade, Serbia \\ ${ }^{2}$ Faculty of Biology, Institute of Botany and Botanical Garden "Jevremovac", University of Belgrade, 11000 Belgrade, Serbia
}

\begin{abstract}
Talaromyces minioluteus is one of the important species of genus Talaromyces, which has cosmopolitan distribution and is encountered on a wide range of different habitats. This species has not been considered as an important plant pathogen, even though it has been isolated from various plant hosts. Fruits and vegetables with Penicillium-like mold symptoms were collected from 2015 to 2017 from markets in Serbia. Isolates originating from quince, tomato, and orange fruits, onion bulbs, and potato tubers were identified and characterized on a morphological, physiological, and molecular level. Morphological and physiological exami-

using four molecular markers: internal transcribed spacer, $\beta$-tubulin, calmodulin, and DNA-dependent RNA polymerase II second largest subunit. The results of morphological and molecular analyses were in agreement, and they proved that the obtained isolates are T. minioluteus. In the pathogenicity assay, $T$. minioluteus was confirmed as a pathogen of all species tested with the exception of potato tubers. This is the first report of $T$. minioluteus as a postharvest plant pathogen on quince, tomato, and orange fruit and onion bulbs. Also, this is the first record of T. minioluteus in Serbia.
\end{abstract} nation included observing micromorphology, testing growth on six different media and at five different temperatures, and production of three enzymes. Molecular identification and characterization were performed
Keywords: Talaromyces minioluteus, postharvest pathogen, identification, characterization, fruits and vegetables
The genus Talaromyces contains polyphagous fungal species with a worldwide distribution. Species of this genus are important as contaminants in food industry, as mycotoxin producers, and in medicine as human pathogens. They are also used in biotechnology for the production of enzymes and soluble pigments and in plant protection as biological control agents (Yilmaz et al. 2014).

Benjamin (1955) introduced the genus Talaromyces to group sexual Penicillium species that produce "soft, usually yellow ascocarps with wall composed of loosely to tightly interwoven hyphae" and have ovate or globose asci and spiny ascospores. However, the genus has recently been redefined and now includes both sexual and asexual species (Samson et al. 2011). In the monograph by Yilmaz et al. (2014), 88 species have been determined in Talaromyces. New species have been described continually since then (Chen et al. 2016; Jiang et al. 2018; Peterson and Jurjević 2017; Visagie et al. 2014a), so now this genus contains 143 species (Rajeshkumar et al. 2019).

One of the important species of this genus, Talaromyces minioluteus, was first described by Dierckx (1901) as Penicillium minioluteum. Later, Raper and Thom (1949) placed this species in synonymy with $P$. funiculosum, which was a decision contrary to the Botanical Code. Pitt (1979) reintroduced P. minioluteum and based its description on isolate FRR 1714. Due to an error in the neotypification of this species it was described later in scientific literature with other two names: P. gaditanum (Ramírez and Martínez 1981) and $P$. samsonii (Quintanilla 1985). P. minioluteum was subsequently retypified and redefined by Van Reenen-Hoekstra et al. (1990) and Frisvad et al. (1990). Samson et al. (2011) analyzed the phenotypic data, extrolite patterns, and multiple-gene phylogeny and transferred all the taxons from the subgenus Biverticillium of

${ }^{\dagger}$ Corresponding author: S. Stošić; stefan.stosic@izbis.bg.ac.rs

Funding: This research was financially supported by the Ministarstvo Prosvete, Nauke i Tehnološkog Razvoja (Ministry of Education, Science and Technological Development of the Republic of Serbia) grants TR 31018 and OI 173032 .

The author(s) declare no conflict of interest.

Accepted for publication 7 November 2019.

(C) 2020 The American Phytopathological Society the genus Penicillium to Talaromyces to follow the new nomenclatural rules. These authors are the first that renamed $P$. minioluteum to $T$. minioluteus, and nowadays all abovementioned names are considered synonyms of the name T. minioluteus (Yilmaz et al. 2014).

T. minioluteus is placed in section Trachyspermi, whose members have restricted growth on Czapek yeast autolysate agar (CYA), yeast extract sucrose agar (YES), and dichloran 18\% glycerol agar (DG18), slightly faster on malt extract agar (MEA), and poor growth on creatine sucrose agar (CREA). They usually have biverticillate conidiophores, and some species of this section produce red pigments. Some of the distinctive features of $T$. minioluteus are moderate growth on general media (CYA, MEA), weak acid production on CREA, and the inability to grow at $37^{\circ} \mathrm{C}$ (Yilmaz et al. 2014).

T. minioluteus has been isolated from the following plant hosts: apple fruits (Quintanilla 1985; Viñas et al. 1993), corn (Camiletti et al. 2014), grape berries (Behr et al. 2013; Khodaei et al. 2016; Sage et al. 2004), pomegranate (Labuda et al. 2004; Palou et al. 2010, 2013), and Tulipa sp. (Van Reenen-Hoekstra et al. 1990). This fungus has also been collected from numerous other substrates and environments: air (Alananbeh et al. 2017; Ramírez and Martínez 1981), declining trees (Kubátová 2000), house dust (Visagie et al. 2014a), pickled onions (Williams 1990), poultry feed (Magnoli et al. 1998), raisins (Khodaei et al. 2016), soil (Hujslová et al. 2010; Lee et al. 2002; Nesci et al. 2006; Okada et al. 1998), tree bark (McGee et al. 2006), jute sugar bags (Van Reenen-Hoekstra et al. 1990), wood (Seifert and Frisvad 2000), and even marine sponge (Ngokpol et al. 2015) and Antarctic mosses (Tosi et al. 2002).

T. minioluteus has also been exploited in chemistry, biochemistry, biotechnology, and other disciplines of science. De Souza et al. (2012) used this species to biotransform clovane derivatives, which have the potential to act as fungistatic agents. Tang et al. (2015) produced novel furanones, miniolins $\mathrm{A}$ to $\mathrm{C}$, using epigenetic manipulation on the culture of $T$. minioluteus. Two spiro-orthoesters, ( \pm )-peniorthoesters A and B, were obtained from T. minioluteus and were the first spiroorthoesters of fungal origin (Liu et al. 2018). This species is a producer of a cell cycle inhibitor (HY 558) that can help in cancer treatment (Lee et al. 2002). Frisvad et al. (2013) noted that T. minioluteus produces red pigments (monascorubrin, rubropunctatin, and other azaphilone pigments), and Sudha et al. (2017) explored the potential and application of the extracted dyes for coloring materials in the textile industry.

T. minioluteus has been considered a postharvest plant pathogen of small economic importance and has limited attention in 
phytopathology. Palou et al. (2010, 2013) investigated postharvest diseases on pomegranate in commercial packinghouses in Spain and among other fungi detected T. minioluteus. Characteristic Penicillium-like blue mold symptoms were noticed on the fruits, and the isolated fungus has been identified using morphological characteristics and gene sequencing. In pathogenicity trials, T. minioluteus did not produce disease symptoms on pomegranate (Palou et al. 2010, 2013). The only confirmation of $T$. minioluteus as a plant pathogen was in the study of Viñas et al. (1993). They explored imazalil resistance of the Penicillium isolates sampled from apple fruits, package boxes, and the air of the storage rooms. Isolates of $T$. minioluteus (referred as $P$. minioluteum) produced decay on the apple fruits in the pathogenicity tests and were among the most resistant to imazalil (Viñas et al. 1993). Furthermore, it has been determined that $T$. minioluteus produces secalonic acid D and F, mycotoxins that can compromise human health (Frisvad et al. 2006; Yilmaz et al. 2014).

According to the available literature, T. minioluteus has not been reported in Serbia. Only two Talaromyces species were detected in Serbia, T. funiculosus and T. rugulosus (reported as Penicillium funiculosum Thom and $P$. rugulosum Thom, respectively), on ready-touse fresh mixed salads (Kocić-Tanackov et al. 2010). The objectives of this study were (i) to examine the etiology of Penicillium-like symptoms on fruits of quince (Cydonia oblonga Mill.), tomato (Solanum lycopersicum L.), and orange (Citrus sinensis [L.] Osbeck), bulbs of onion (Allium cepa L.), and tubers of potato (Solanum tuberosum L.); (ii) to identify and characterize isolates of T. minioluteus by using morphological, physiological, and molecular methods; (iii) to investigate the relationship of Serbian isolates of $T$. minioluteus and their placement within the section Trachyspermi of genus Talaromyces by sequencing four genetic loci of ribosomal DNA and protein coding regions (internal transcribed spacer [ITS], $\beta$-tubulin [BenA], calmodulin [ $\mathrm{CaM}$, and DNA-dependent RNA polymerase II second largest subunit [RPB2]); and (iv) to evaluate pathogenicity of the isolates on the originating hosts.

\section{Materials and Methods}

Sampling and isolation. Various samples of fruits and vegetables with Penicillium-like mold symptoms - brown, watery spots or characteristic blue/green sporulation on their surface-were randomly collected from markets in 2015 to 2017. Three hundred twenty-one samples were recovered, and all originated from Serbia, except the citrus fruits (Table 1).

Three small pieces on the border of necrotic and healthy tissue of each sample were excised with a sterilized scalpel, sterilized in $1 \%$ aqueous solution of $\mathrm{NaOCl}$ for $2 \mathrm{~min}$, rinsed three times with sterile distilled water, placed on MEA, and incubated in dark conditions for 7 days at $25^{\circ} \mathrm{C}$. Single-spore isolates were obtained, transferred onto potato dextrose agar slants, and kept at $4^{\circ} \mathrm{C}$. Eight isolates were chosen for comprehensive investigation (Table 1). The number of selected isolates per host corresponded to the relative frequency of the isolates determined on the originating plant hosts.

Cultivation conditions. Isolates included in the analysis were three-point inoculated by placing $1 \mu l$ of conidial suspension from semisolid agar $(0.2 \%$ agar and $0.05 \%$ Tween 80$)$ in $90-\mathrm{mm}$ Petri dishes on CYA, MEA, CREA, YES, DG18, and oatmeal agar (OA) and incubated for 7 days in the dark at $25^{\circ} \mathrm{C}$ (Visagie et al. 2014b; Yilmaz et al. 2014). The impact of temperature on fungal growth was examined by incubating cultures for 7 days at 5, 15, 30 , and $37^{\circ} \mathrm{C}$ on CYA. After the incubation, all plates were photographed (Olympus digital camera, model FE-220/X-785, Olympus Corporation, Japan), two perpendicular diameters were measured for each colony, and the average was calculated. Phenotypic characteristics such as culture appearance and mycelium color (obverse, reverse), colony texture, sporulation, presence and color of exudates, diffusible color, and change of the medium color were also recorded.

Microscopic investigation. Preparation of microscopic slides was done from 10-day-old cultures grown on MEA. The conidia were suspended in $1 \mathrm{ml}$ of $60 \%$ lactic acid (Yilmaz et al. 2014). Phenotypic characteristics of conidia (shape, ornamentation of the cell wall) and conidiophores (number of branching points between stipe and phialides, shape and texture of phialides) were recorded. Microscopic examinations were done using an Olympus phase contrast microscope (model BX51) and photographed using an Olympus camera (model E620). Two diameters (length and width) were measured for 100 conidia of each isolate in the Quick Photo Camera software program (PROMICRA, Czech Republic).

Lipase, esterase, and amylase production test. All isolates were assayed for lipase, esterase, and amylase production. Lipase production was tested using spirit blue agar and lipase reagent (Difco, BD, Franklin Lakes, NJ) (Pianzzola et al. 2004). Esterase production was examined using Tween 80 medium. Amylase production was assessed using a medium with starch (Paterson and Bridge 1994). Each isolate was inoculated by placing $25 \mu \mathrm{l}$ of conidial suspension from semisolid agar in the center of $90-\mathrm{mm}$ Petri dishes containing the abovementioned media and incubated in the dark at $25^{\circ} \mathrm{C}$. Reactions were recorded after 7 days with the lipase production test and after 10 days for esterase and amylase production. In the lipase production test, a positive reaction was the manifestation of a halo effect around the culture. In the esterase production test, a positive reaction was the change of medium color from green to blue-purple. In the amylase production test, a positive reaction was growth on this medium and manifestation of a brown ring around the culture appearing 5 to $10 \mathrm{~min}$ after flooding them with $4 \mathrm{ml}$ of Lugol's solution.

DNA extraction. The isolates were cultivated for 7 days at $25^{\circ} \mathrm{C}$ in the dark on MEA for DNA extraction. Approximately $100 \mathrm{mg}$ of mycelium was scraped from the surface of the plate using a sterile blade, transferred to a $1.5-\mathrm{ml}$ sample tube, frozen in liquid nitrogen, and ground using a sterile micropestle. DNA extractions were performed using a DNeasy Plant Mini Kit (Qiagen, Hilden, Germany) according to the manufacturer's instructions, and the extracts were kept at $-20^{\circ} \mathrm{C}$.

Polymerase chain reaction (PCR). PCR was performed for four molecular markers: ITS, BenA, CaM, and RPB2 (Table 2). Total volume of reactions was $40 \mu \mathrm{l}$ for each individual marker. PCR reactions for ITS and partial BenA amplification contained $20 \mu \mathrm{l}$ of $2 \times$ PCR Master mix (TaqNova-RED: $4 \mathrm{mM} \mathrm{MgCl}_{2} ; 1.6 \mathrm{mM}$ dNTPs mix [0.4 mM of each $\mathrm{dNTP}$ ]; $0.04 \mathrm{U} / \mu \mathrm{l}$ TaqNova DNA polymerase; DNA Gdansk, Poland), $4 \mu \mathrm{l}$ of each primer (Microsynth AG, Switzerland, for ITS; Metabion International AG, Germany, for BenA), $10.4 \mu \mathrm{l}$ of sterile nuclease-free water (Thermo Fisher Scientific, U.S.A.), and $1.6 \mu \mathrm{l}$ of DNA. The compounds for CaM gene amplification were $20 \mu$ l of $2 \times$ PCR Master mix (TaqNova-RED, DNA Gdansk), $8 \mu$ l of each primer (Microsynth), $2.4 \mu l$ of sterile nuclease-free water, and $1.6 \mu 1$ of DNA. In $R P B 2$ gene amplification, reagents in PCR reaction were $4 \mu$ of PCR buffer (without $\mathrm{MgCl}_{2}$ ), $28.9 \mu \mathrm{l}$ of sterile nuclease-free water, 1.6 of $\mathrm{MgCl}_{2}(50 \mathrm{mM})$ (Invitrogen, Thermo Fisher Scientific), $1.6 \mu \mathrm{l}$ of dNTPs (1 mM) (DNA

Table 1. Metadata associated with the Talaromyces spp. isolates included in this study

\begin{tabular}{llcc}
\hline Year & Sample type & $\begin{array}{c}\text { No. of collected } \\
\text { samples/no. of } \\
\text { Talaromyces } \\
\text { spp. isolates }\end{array}$ & $\begin{array}{c}\text { Isolates } \\
\text { included } \\
\text { in the analysis }\end{array}$ \\
\hline $2015-2017$ & Apple fruit & $54 /-$ & - \\
$2015-2016$ & Quince fruit & $31 / 4$ & DnjP/2 \\
$2015-2016$ & Pear fruit & $43 /-$ & - \\
$2015-2016$ & Onion bulb & $48 / 13$ & CLP/3 \\
& & & CLP/4 \\
& & & CLP/5 \\
2016-2017 & Tomato fruit & $25 / 3$ & CLP/7 \\
2016 & Potato tuber & $6 / 2$ & ParP/2 \\
$2015-2016$ & Lemon fruit & $39 /-$ & - \\
$2016-2017$ & Orange fruit & $35 / 4$ & PP/14 \\
$2016-2017$ & Mandarin fruit & $40 /-$ & - \\
Total & & $321 / 26$ & 8 \\
\hline
\end{tabular}


Gdansk), $0.8 \mu \mathrm{l}$ of each primer (Invitrogen, Thermo Fisher Scientific), $0.3 \mu \mathrm{l}$ of Taq polymerase (KAPATaq, KAPA Biosystems, Roche Holding AG, Switzerland), and $2 \mu$ l of DNA. Amplifications were conducted in an Eppendorf thermal cycler Mastercycler nexus GSX1 (Eppendorf, Germany). PCR cycling conditions are presented in Table 2. Electrophoretic mobility of the amplified DNA products $(10 \mu \mathrm{l})$ was tested in $1 \%$ agarose gel at $110 \mathrm{~V}$ for $45 \mathrm{~min}$ (stained with Midori green dye, Bulldog Bio, U.S.A.) and visualized with a UV transilluminator (Vilber Lourmat UV transilluminator, Germany).

Sequencing and sequence analysis. The PCR products of all genomic regions were purified and sequenced in both directions in an automated sequencer (ABI 3730XL Automatic Sequencer, Macrogen, South Korea), using the same primers as for the amplification. Consensus sequences were computed using the ClustalW algorithm (Thompson et al. 1994), integrated in MEGA7 software (Kumar et al. 2016), and deposited in GenBank (Table 3). All generated sequences were compared with each other by calculating nucleotide identities, as well as with previously deposited $T$. minioluteus isolates available in the GenBank, using the similarity search tool, BLAST.

Phylogenetic analysis. Newly generated ITS, BenA, CaM, and $R P B 2$ sequences were analyzed with reference sequences of Talaromyces section Trachyspermi available in NCBI and previously listed type-derived sequences of Talaromyces spp. (Rajeshkumar et al. 2019). The analyses of individual gene alignments for the purpose of identification of Serbian isolates and the analyses of concatenated four gene alignments for the purpose of characterization were performed using MEGA7 software (Kumar et al. 2016).

Phylogenetic trees were inferred using the maximum likelihood implemented in MEGA version 7.0 software (Kumar et al. 2016) on individual as well as combined datasets of ITS, BenA, CaM, and $R P B 2$ gene sequences. The sequence of $T$. pinophilus (CBS 631.66) was used as an outgroup. The gamma-distributed Tamura-Nei model $(\mathrm{G}+\mathrm{I})$ determined by Modeltest implemented in MEGA7 was used as the best fitting model of nucleotide substitution. The reliability of the obtained trees was evaluated using 1,000 bootstrap replicates, and bootstrap confidence values $<70 \%$ were omitted. Phylogenetic trees were visually prepared and edited in Adobe Photoshop CS6 (Adobe, U.S.A.).

Pathogenicity test. Pathogenicity of our isolates was tested on intact, symptomless quince, tomato, and orange fruits, onion bulbs, and potato tubers. The assay was conducted only on hosts from which isolates were obtained. The fruits, tubers, and bulbs were surface sterilized with $70 \%$ ethanol, air dried, wounded with a sterile needle, and inoculated with $50 \mu \mathrm{l}$ of spore suspension. Conidial suspensions for each isolate were prepared in $1 \mathrm{ml}$ of sterile distilled water from the 14-day-old cultures grown on MEA. The spore concentration was determined with a hemocytometer (Neubauer chamber) and adjusted to $1 \times 10^{6}$ conidia $/ \mathrm{ml}$. Each host was inoculated in three replicates with the corresponding isolate. Control fruits, tubers, and bulbs were inoculated with $50 \mu \mathrm{l}$ of sterile distilled water. All inoculated hosts were placed in a plastic container and incubated at $25^{\circ} \mathrm{C}$ and $95 \%$ relative air humidity. Symptoms were assessed 7 days after inoculation by measuring the horizontal and vertical (stem-calyx axis vertical) diameters of lesions. To confirm that symptoms were caused by $T$. minioluteus, reisolations were done from $100 \%$ of the inoculated fruits, tubers, and bulbs. Reisolation was performed as described above (see "Sampling and isolation"). Colony and spore morphology of the developed MEA cultures was checked for the fulfillment of Koch's postulates. Inoculated fruits, bulbs, and tubers were monitored after the expiration of the specified incubation period to observe further symptom development. The experiment was performed twice, and it was arranged according to a completely randomized design.

Statistical analysis. Data were analyzed in IBM SPSS Statistics, version 23 (IBM Corporation, U.S.A.). Data from independent experiments were pooled if the individual trials proved not to be significantly different. Basic descriptive statistics (minimal, maximal, and average diameters, standard deviation) were calculated for colony growth of all tested isolates on the above-named six media and five temperatures. Mean diameters for colony growth and lesions in the pathogenicity assay were analyzed by one-way ANOVA $(P \leq$ 0.05 ) and then compared and separated using Tukey's honest significant difference test. Levene's test for homogeneity of variance was used. In cases in which the condition of the equality of variances was not fulfilled, we applied more robust Welch and Brown-Forsythe tests to compare the growth diameters. Minimal, maximal, and average length and width were calculated for conidia.

\section{Results}

Symptoms and fungal isolation. Penicillium-like mold symptoms were observed on all collected types of fruit and vegetables. Discoloration of the tissue, brown, circular, slightly sunken spots, presence of white to yellow mycelia, and in some cases sparse to intensive sporulation with dark green spores on the surface of samples were recorded. The decayed area was soft and watery.

After isolation on MEA, 26 isolates were obtained with significantly different morphological characteristics (colony color and texture, very slow growth and micromorphology) in comparison with the other obtained single-conidial isolates of Penicillium spp. (unpublished data). For detailed morphological and molecular identification and characterization, eight isolates originating from quince, tomato, and orange fruits, onion bulbs, and potato tubers were chosen (Table 1).

Growth on different media. Each isolate was inoculated on six media (CYA, MEA, CREA, DG18, OA, and YES) and incubated for 7 days at $25^{\circ} \mathrm{C}$. The results of the radial growth diameters and the macromorphological characteristics are presented in Figures 1A and $2 \mathrm{~A}$ to $\mathrm{K}$, respectively. All tested isolates had plane, compact colonies on CYA, DG18, OA, and YES, plane-filamentous on CREA, and slightly umbonate on MEA. Textures were velutinous on CYA, DG18, and CREA, strongly funiculose on MEA and YES, and loosely funiculose on OA. Mycelia were visible on the edges of the cultures, white on DG18, whiteish on CYA, white to yellowish on MEA and OA, and transparent to white on CREA. Sporulation was abundant on all media, except on CREA, for which it was moderate. Conidia were dark green on CYA, YES, CREA, DG18, and

Table 2. List of primers and PCR conditions used in molecular identification of Serbian Talaromyces spp. isolates

\begin{tabular}{|c|c|c|c|c|c|}
\hline Locus & $\begin{array}{l}\text { Primer } \\
\text { set }\end{array}$ & Direction & Primer sequence $\left(5^{\prime}-3^{\prime}\right)$ & Reference & Cycling conditions \\
\hline \multirow[t]{2}{*}{ Internal transcribed spacer (ITS) } & V9G & Forward & TTACGTCCCTGCCCTTTGTA & $\begin{array}{l}\text { de Hoog and van den } \\
\text { Ende (1998) }\end{array}$ & \multirow{4}{*}{$\begin{array}{l}94^{\circ} \mathrm{C}, 5 \mathrm{~min} ; 94^{\circ} \mathrm{C}, 45 \mathrm{~s}, 55^{\circ} \mathrm{C}, \\
45 \mathrm{~s}, 72^{\circ} \mathrm{C}, 1 \mathrm{~min}(35 \\
\text { cycles); } 72^{\circ} \mathrm{C} \text { for } 7 \mathrm{~min}\end{array}$} \\
\hline & LS266 & Reverse & GCATTCCCAAACAACTCGACTC & Masclaux et al. (1995) & \\
\hline \multirow[t]{2}{*}{ Calmodulin $(\mathrm{CaM})$} & CMD5 & Forward & CCGAGTACAAGGARGCCTTC & \multirow[t]{2}{*}{ Hong et al. (2006) } & \\
\hline & CMD6 & Reverse & CCGATRGAGGTCATRACGTGG & & \\
\hline \multirow[t]{2}{*}{$\beta$-tubulin $(B e n A)$} & $\mathrm{Bt} 2 \mathrm{a}$ & Forward & GGTAACCAAATCGGTGCTGCTTTC & \multirow{2}{*}{$\begin{array}{l}\text { Glass and Donaldson } \\
\text { (1995) }\end{array}$} & \multirow{2}{*}{$\begin{array}{c}94^{\circ} \mathrm{C}, 5 \mathrm{~min} ; 94^{\circ} \mathrm{C}, 30 \mathrm{~s}, 55^{\circ} \mathrm{C}, \\
45 \mathrm{~s}, 72^{\circ} \mathrm{C}, 1 \mathrm{~min}(35 \\
\text { cycles }) ; 72^{\circ} \mathrm{C}, 7 \mathrm{~min}\end{array}$} \\
\hline & $\mathrm{Bt} 2 \mathrm{~b}$ & Reverse & ACCCTCAGTGTAGTGACCCTTGGC & & \\
\hline \multirow{2}{*}{$\begin{array}{l}\text { DNA-dependent RNA polymerase II } \\
\text { second largest subunit }(R P B 2)\end{array}$} & $5 \mathrm{~F}$ & Forward & GAYGAYMGWGATCAYTTYGG & \multirow[t]{2}{*}{ Liu et al. (1999) } & \multirow{2}{*}{$\begin{array}{l}94^{\circ} \mathrm{C}, 5 \mathrm{~min} ; 94^{\circ} \mathrm{C}, 45 \mathrm{~s}, 60^{\circ} \mathrm{C}, \\
45 \mathrm{~s}, 72^{\circ} \mathrm{C}, 1 \mathrm{~min}(35 \\
\text { cycles }) ; 72^{\circ} \mathrm{C}, 7 \mathrm{~min}\end{array}$} \\
\hline & $7 \mathrm{CR}$ & Reverse & CCCATRGCTTGYTTRCCCAT & & \\
\hline
\end{tabular}


$\mathrm{OA}$ and bluish-green on MEA. Margins were low, entire, and up to $2 \mathrm{~mm}$ wide on all media, except on CREA, for which they were filiform. Acid production on CREA was absent or very weak (weak change of the medium color from purple to yellow). Exudates and soluble pigments were absent on all media. On the reverse side of the plates, cultures were light yellowish green on CYA, light cream yellow on MEA and OA, pale green on DG18, orange on YES, and light dull green on CREA.

Significant differences $(P \leq 0.05)$ were determined among isolates grown on the same medium on CYA, YES, OA, and DG18 (Fig. 1A). Growth diameters were not significantly different on MEA and CREA. All isolates had the fastest growth on YES (from 22.67 to $28 \mathrm{~mm}$, isolates CLP/4 and DnjP/2, respectively) and the slowest on CREA (6.33 to $8.42 \mathrm{~mm}$, isolates ParP/2 and CLP/4, respectively). The isolate from orange fruit (PP/14) had the slowest mycelial growth on three of the six tested media (CYA, MEA, and $\mathrm{OA})$. The isolate from tomato (ParP/2) had the fastest growth on $\mathrm{CYA}$ and $\mathrm{OA}$, and the isolate from quince $(\mathrm{DnjP} / 2)$ was the fastest growing on YES and CREA.

Growth on CYA at different temperatures. At 5 and $37^{\circ} \mathrm{C}$ none of the tested isolates manifested growth (Fig. 1B). Significant differences $(P \leq 0.05)$ were detected in growth at the remaining three temperatures. Also, colony morphology was different at these temperatures: cultures had one appearance at $15^{\circ} \mathrm{C}$ and another at 25 and $30^{\circ} \mathrm{C}$. Colonies of all isolates at $15^{\circ} \mathrm{C}$ were raised, with very slow growth, white or somewhat yellowish mycelia, floccose texture, absent or very weak sporulation, and no exudates. Margins were white and entire. Reverse, cultures were orange-brown. At 25 and $30^{\circ} \mathrm{C}$, colonies had similar appearance to cultures on CYA described in the previous section. The only difference was that at $30^{\circ} \mathrm{C}$ soluble pigments (light yellow color) were visible in $\mathrm{PP} / 14$ (isolate from orange) and in CLP/3 (isolate from onion).

The fastest growth of all isolates was recorded at $30^{\circ} \mathrm{C}$, and the slowest was at $15^{\circ} \mathrm{C}$ (Fig. 1B). The mean radial growth diameters at $15^{\circ} \mathrm{C}$ ranged from $2.75 \mathrm{~mm}$ (isolate $\mathrm{PP} / 14$ ) to $4.71 \mathrm{~mm}(\mathrm{ParP} / 2)$ (Fig. 1B). At $25^{\circ} \mathrm{C}$ mycelial growth was in the range from $15.33 \mathrm{~mm}$ (isolate $\mathrm{PP} / 14$ ) to $19.08 \mathrm{~mm}(\mathrm{ParP} / 2)$. The average growth diameters at $30^{\circ} \mathrm{C}$ were in the range from $18.67 \mathrm{~mm}$ (isolate CLP/3) to $21.25 \mathrm{~mm}(\mathrm{ParP} / 2)$. Isolate PP/14 from orange had the least rapid growth at two $\left(15\right.$ and $\left.25^{\circ} \mathrm{C}\right)$ out of three temperatures, and isolate $\mathrm{ParP} / 2$ from tomato had the fastest growth at all three temperatures for which growth was registered.

Microscopic investigation. All analyzed isolates originating from various hosts formed biverticillate conidiophores, with smooth stipes and acerose phialides. Conidia were smooth-walled and ellipsoidal to subglobose (Fig. 2L). Conidia sizes ranged from $2.49 \times 2.35 \mu \mathrm{m}$

Table 3. Accession numbers for Talaromyces spp. isolates used in the phylogenetic analysis; isolates from this study are in bold ${ }^{\mathrm{a}}$

\begin{tabular}{|c|c|c|c|c|c|c|}
\hline \multirow[b]{2}{*}{ Species } & \multirow[b]{2}{*}{ Strain/isolate } & \multirow[b]{2}{*}{ Substrate and origin } & \multicolumn{4}{|c|}{ GenBank accessions } \\
\hline & & & ITS & BenA & $\mathrm{CaM}$ & $R P B 2$ \\
\hline T. aerius & CBS $140611^{\mathrm{T}}$ & Indoor air, China & KU866647 & KU866835 & KU866731 & KU866991 \\
\hline \multirow[t]{2}{*}{ T. albobiverticillius } & CBS $133440^{\mathrm{T}}$ & Decaying leaves of a broad-leaved tree, Taiwan & HQ605705 & KF114778 & KJ885258 & KM023310 \\
\hline & CBS 140498 & Air from HVAC system, China & KR855658 & KR855648 & KR855653 & KR855663 \\
\hline \multirow[t]{2}{*}{ T. amyrossmaniae } & NFCCI $1919^{\mathrm{T}}$ & $\begin{array}{l}\text { Fallen decaying fruits of Terminalia bellirica } \\
\text { (Combretaceae), Maharashtra, India }\end{array}$ & MH909062 & MH909064 & MH909068 & MH909066 \\
\hline & NFCCI 2351 & $\begin{array}{l}\text { Fallen decaying fruits of Terminalia bellirica } \\
\text { (Combretaceae), Maharashtra, India }\end{array}$ & MH909063 & MH909065 & MH909069 & MH909067 \\
\hline \multirow[t]{2}{*}{ T. assiutensis } & CBS $147.78^{\mathrm{T}}$ & Soil, Egypt & JN899323 & KJ865720 & KJ885260 & KM023305 \\
\hline & CBS 645.80 & Gossypium, India & JN899334 & KF114802 & & $*$ \\
\hline \multirow[t]{2}{*}{ T. atroroseus } & CBS $133442^{\mathrm{T}}$ & House dust, South Africa & KF114747 & KF114789 & KJ775418 & КM023288 \\
\hline & CBS 133449 & Mouse dung, Denmark & KF114744 & KF114788 & $*$ & $*$ \\
\hline T. austrocalifornicus & CBS $644.95^{\mathrm{T}}$ & Soil, U.S.A. & JN899357 & KJ865732 & KJ885261 & $*$ \\
\hline T. brasiliensis & CBS $142493^{\mathrm{T}}$ & $\begin{array}{l}\text { Honey of Melipona scutellaris, Recife, } \\
\text { Pernambuco, Brazil }\end{array}$ & MF278323 & LT855560 & LT855563 & LT855566 \\
\hline T. convolutus & CBS $100537^{\mathrm{T}}$ & Soil, Nepal & JN899330 & KF114773 & $*$ & JN121414 \\
\hline \multirow{2}{*}{ T. diversus } & CBS $320.48^{\mathrm{T}}$ & Leather, U.S.A. & KJ865740 & KJ865723 & KJ885268 & KM023285 \\
\hline & DTO 244-E6 & House dust, New Zealand & KJ775712 & KJ775205 & $*$ & * \\
\hline T. erythromellis & CBS $644.80^{\mathrm{T}}$ & Soil from creek bank, New South Wales, Australia & JN899383 & HQ156945 & KJ885270 & KM023290 \\
\hline T. heiheensis & HMAS $248789^{\mathrm{T}}$ & Rotten wood, China & KX447526 & KX447525 & KX447532 & KX447529 \\
\hline \multirow[t]{11}{*}{ T. minioluteus } & CBS $642.68^{\mathrm{T}}$ & Unknown & JN899346 & KF114799 & KJ885273 & JF417443 \\
\hline & CBS 270.35 & Zea mays, U.S.A. & KM066172 & KM066129 & $*$ & $*$ \\
\hline & CBS 137.84 & Fruit damaged by insect, Spain & KM066171 & KF114798 & $*$ & * \\
\hline & CLP/3 & Onion, Serbia & MN311444 & MN306500 & MN306508 & MN306516 \\
\hline & CLP/4 & Onion, Serbia & MN311445 & MN306501 & MN306509 & MN306517 \\
\hline & CLP/5 & Onion, Serbia & MN311446 & MN306502 & MN306510 & MN306518 \\
\hline & CLP/7 & Onion, Serbia & MN311447 & MN306503 & MN306511 & MN306519 \\
\hline & DnjP/2 & Quince, Serbia & MN311448 & MN306504 & MN306512 & MN306520 \\
\hline & KroP/1 & Potato, Serbia & MN311449 & MN306505 & MN306513 & MN306521 \\
\hline & $\mathrm{ParP} / 2$ & Tomato, Serbia & MN311450 & MN306506 & MN306514 & MN306522 \\
\hline & PP/14 & Orange, Serbia & MN311451 & MN306507 & MN306515 & MN306523 \\
\hline T. minnesotensis & CBS $142381^{\mathrm{T}}$ & Human ear, U.S.A. & LT558966 & LT559083 & LT795604 & LT795605 \\
\hline \multirow[t]{2}{*}{ T. solicola } & DAOM $241015^{\mathrm{T}}$ & Soil, South Africa & FJ160264 & GU385731 & KJ885279 & KM023295 \\
\hline & CBS 133446 & Soil, South Africa & KF114730 & KF114775 & $*$ & $*$ \\
\hline T. systylus & BAFCcult $3419^{\mathrm{T}}$ & Soil, Argentina & KР026917 & KR233838 & KR233837 & $*$ \\
\hline \multirow[t]{2}{*}{ T. trachyspermus } & CBS $373.48^{\mathrm{T}}$ & Unknown, U.S.A. & JN899354 & KF114803 & KJ885281 & JF417432 \\
\hline & CBS 118437 & Soil, Morocco & KM066169 & KM066127 & $*$ & $*$ \\
\hline \multirow[t]{2}{*}{ T. ucrainicus } & CBS $162.67^{\mathrm{T}}$ & Unknown & JN899394 & KF114771 & KJ885282 & KM023289 \\
\hline & CBS 127.64 & $\begin{array}{l}\text { Soil treated with cyanimide, Germany } \\
\text { (ex-type of } T \text {. ohiensis) }\end{array}$ & KM066173 & KF114772 & $*$ & $*$ \\
\hline T. udagawae & CBS $579.72^{\mathrm{T}}$ & Soil, Japan & JN899350 & KF114796 & KX961260 & $*$ \\
\hline
\end{tabular}

\footnotetext{
${ }^{a}$ Superscript T indicates an ex-type strain. Asterisks indicate no corresponding entry exists. ITS = internal transcribed spacer; $C a M=$ calmodulin; BenA = $\beta$-tubulin;
} and $R P B 2=$ DNA-dependent RNA polymerase II second largest subunit. 
$(\mathrm{CLP} / 7)$ to $3.73 \times 3.34 \mu \mathrm{m}(\mathrm{KroP} / 1)($ Table 4$)$. Ascomata were not observed.

Micromorphological features, colony morphology, and growth diameters on tested media and temperatures are in agreement with the description of species T. minioluteus (Visagie 2012; Yilmaz et al. 2014).

Production of lipase, esterase, and amylase. In enzyme production tests all tested isolates manifested similar reactions, with minor differences (Table 4). In the lipase production test, all isolates had a negative result except the isolate ParP/2 from tomato fruit, for which very small brightness of the medium color around the culture was noticed. Tested isolates expressed a negative reaction in the esterase production assay. In the amylase production test, all isolates had weak growth on Tween 80 medium, and the margins of the cultures were brown, which was considered a weak positive reaction. Isolates DnjP/2 (from quince fruit) and KroP/1 (from potato tuber) had

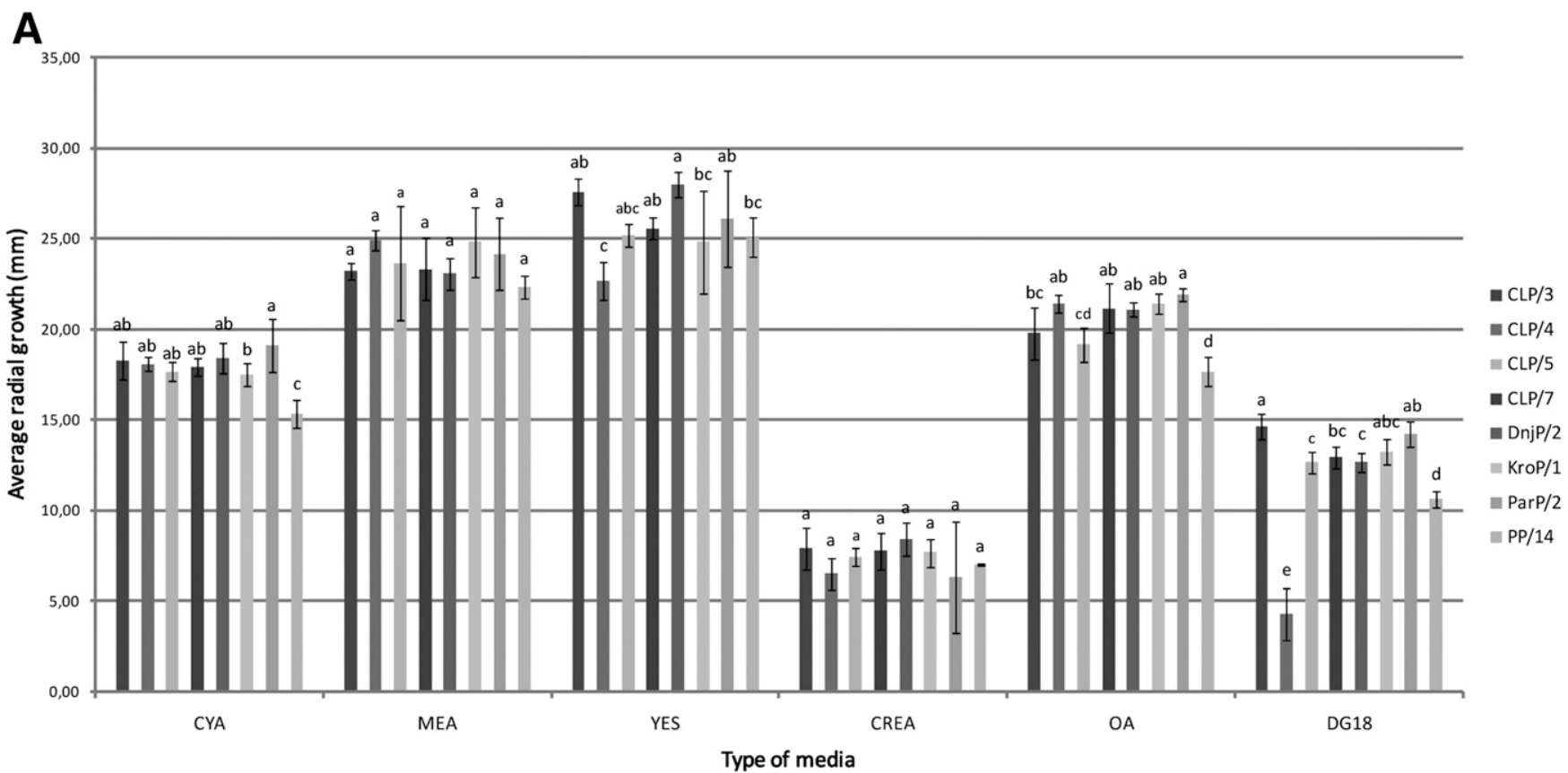

B

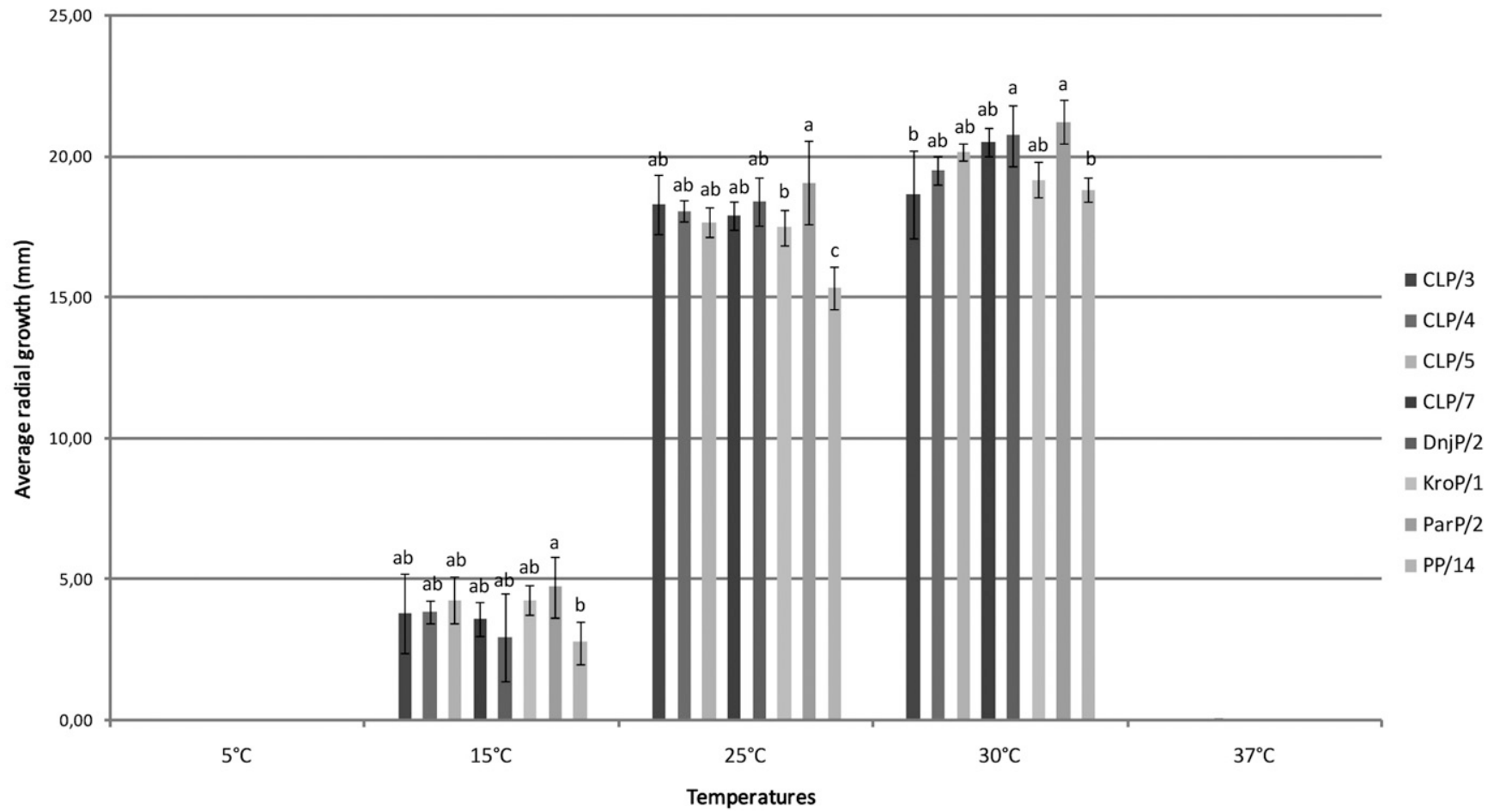

Fig. 1. The average colony growth of Talaromyces minioluteus isolates. A, Growth on six media after 7 days of incubation at $25^{\circ} \mathrm{C}$. Numbers followed by the same letters in the column for Czapek yeast autolysate agar (CYA) represent values that are not significantly different according to Tukey's HSD test $(P \leq 0.05)$; numbers followed by the same letters in the column for malt extract agar (MEA) represent values that are not significantly different according to the Brown-Forsythe test $(P \leq 0.05)$; numbers followed by the same letters in the columns for yeast extract sucrose agar (YES), creatine sucrose agar (CREA), oatmeal agar (OA), and dichloran 18\% glycerol agar (DG18) represent values that are not significantly different according to the Welch test $(P \leq 0.05)$. Vertical error bars on all media type indicate standard deviation of the mean (SD). B, Growth on CYA at five different temperatures. Numbers with the same letters represent values that are not significantly different according to Tukey's HSD test $(P \leq 0.05)$. Vertical error bars indicate SD. 
slightly different reactions than the others: DnjP/2 had a narrow brown zone around the culture (weaker reaction), and KroP/1 had a clear positive reaction.

Molecular identification and sequence analysis. All eight ITS sequences from Serbian isolates were similar (99.9 to 100\%; 1 bp difference) to each other. BLAST analysis revealed the highest nucleotide identities of $99.2 \%$ with one sequence of $T$. minioluteus from Spain (MH861709). The BenA sequences of our T. minioluteus isolates shared a similarity of 99.8 to $100 \%$ (1 bp differences), and BLAST results revealed a nucleotide identity of 99.8 to $100 \%$ with five T. minioluteus isolates from Iran (KU516400 to 404). The CaM sequences of all eight Serbian T. minioluteus isolates proved to be $100 \%$ identical at the nucleotide level, and BLAST analysis confirmed the highest nucleotide homology of $99.6 \%$ with one $T$. minioluteus from Iran (KU711896). The RPB2 sequences of Serbian isolates showed nucleotide identities of 99.9 to $100 \%$ (1 bp differences), and BLAST analysis confirmed the highest nucleotide homology of $99 \%$ with one T. minioluteus isolate from Brazil (KX650058). BLAST analyses of all four targeted genome regions (ITS, BenA, CaM, and RPB2) confirmed the conventional identification based on morpho-physiological characteristics of selected Serbian T. minioluteus isolates.

Molecular characterization and phylogeny. Maximum likelihood analyses of the ITS, BenA, CaM, and RPB2 sequences alignment of 475, 370, 487, and 517 nucleotides each, including the outgroup taxa, resulted in phylogenetic trees with established resolution and topology for species of section Trachyspermi (Fig. 3). In the ITS phylogeny, the Serbian isolates were placed in a single distant branch with high bootstrap support (98\%) from the main clade with the rest of T. minioluteus isolates, showing a similarity of 99.1, 98.9, and $98.7 \%$, respectively, to CBS 137.84 , CBS 270.35, and CBS 642.68. Our isolates were positioned in the BenA phylogeny in a single distant branch with high bootstrap support (99\%) from the main clade with the rest of $T$. minioluteus isolates, showing a similarity of 95.3, 94.7, and 94\%, respectively, to CBS 642.68, CBS 270.35, and CBS 137.84. In the CaM and RPB2 phylogeny our isolates had 95.8 and $97.8 \%$ sequence similarity with the sequence of CBS 642.68 with high bootstrap support (100\%). Also, our isolates were clustered with T. minnesotensis and T. udagawae in the ITS, BenA, CaM, and $R P B 2$ analyses.

Multilocus analysis, based on the Tamura-Nei model assuming gamma distribution (Kumar et al. 2016), resulted in a maximum likelihood tree for the four concatenated loci (Fig. 4). The ITS, BenA, $C a M$, and $R P B 2$ sequence alignments consisted of $475,370,487$, and 517 nucleotides, respectively (1,849 nucleotides in total), from 37 different isolates, including the outgroup taxa. At the Trachyspermi section level, the phylogenetic tree with the combined data set shared a similar topology with the ITS, BenA, CaM, and RPB2 single-locus trees obtained in this study. Within the clade, T. minioluteus isolates were, with great confidence, separated in two subgroups (bootstrap support of $100 \%$ ). The first branch included the Serbian isolates, whereas the remaining $T$. minioluteus isolates from the United States, Spain, and one unknown location were grouped in the second branch. These isolates were included in a highly supported clade with T. minnesotensis and T. udagawae.

Pathogenicity test. Tested T. minioluteus isolates manifested rot symptoms on quince, tomato, and orange fruits and onion bulbs 7 days after inoculation (Fig. 5A to $\mathrm{H}$ ). Our assay showed that $T$. minioluteus (isolate KroP/1) was not pathogenic on potato tubers (Fig. 5I and J). Control fruits remained without symptoms. Significant
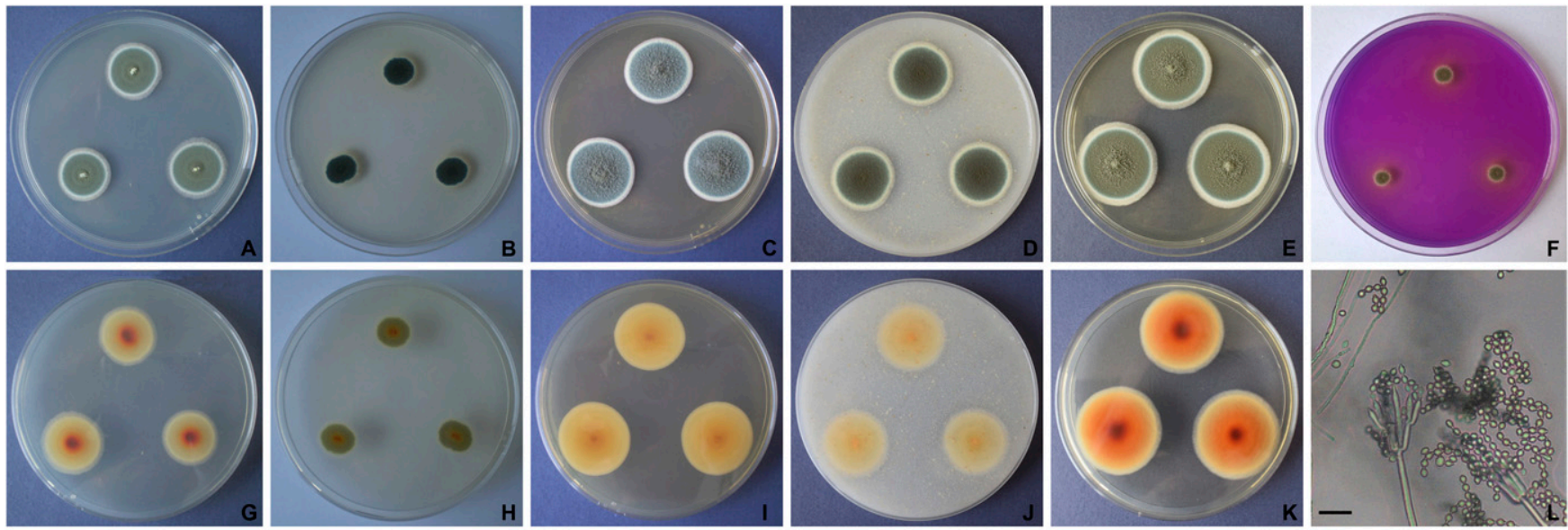

Fig. 2. Morphological characteristics of Talaromyces minioluteus isolate DnjP/2. Obverse: A, Czapek yeast autolysate agar (CYA); B, dichloran 18\% glycerol agar (DG18); C, malt extract agar (MEA); D, oatmeal agar (OA); E, yeast extract sucrose agar (YES); and F, creatine sucrose agar (CREA). Reverse: G, CYA; H, DG18; I, MEA; J, OA; and K, YES. L, Conidiophores and conidia, bar $=10 \mu \mathrm{m}$.

Table 4. Dimensions of spores and enzyme production of Talaromyces minioluteus isolates

\begin{tabular}{|c|c|c|c|c|}
\hline \multirow[b]{2}{*}{ Isolate } & \multirow{2}{*}{$\begin{array}{c}\text { Conidial dimensions }(\mu \mathrm{m}), \\
\text { minimum-(average)-maximum }\end{array}$} & \multicolumn{3}{|c|}{ Enzyme production } \\
\hline & & Lipase test $^{\mathbf{a}}$ & Esterase test $^{\mathbf{b}}$ & Amylase test ${ }^{c}$ \\
\hline $\mathrm{CLP} / 3$ & $3.00-(3.08)-4.00 \times 2.00-(2.65)-3.00$ & - & - & +- \\
\hline CLP/4 & $3.00-(3.04)-4.00 \times 2.00-(2.72)-3.00$ & - & - & +- \\
\hline CLP/5 & $2.00-(2.51)-2.75 \times 2.25-(2.46)-2.75$ & - & - & +- \\
\hline CLP/7 & $2.25-(2.54)-3.00 \times 2.25-(2.54)-3.00$ & - & - & +- \\
\hline DnjP/2 & $2.25-(2.61)-3.75 \times 2.00-(2.50)-3.00$ & - & - & + \\
\hline $\mathrm{KroP} / 1$ & $2.00-(2.49)-3.00 \times 2.00-(2.35)-2.75$ & - & - & + \\
\hline $\mathrm{ParP} / 2$ & $3.00-(3.11)-4.00 \times 2.00-(2.52)-3.00$ & + & - & +- \\
\hline $\mathrm{PP} / 14$ & $2.50-(3.73)-5.00 \times 2.50-(3.34)-5.00$ & - & - & +- \\
\hline
\end{tabular}

a $-=$ no halo effect; $+=$ strong halo effect; and $+-=$ weak halo effect.

$\mathrm{b}_{-}=$medium color green; and $+=$medium color purple-blue.

$c_{-}=$blue zone around the culture; $+=$brown zone around the culture; and $+-=$margin of the culture is brown. 
differences $(P \leq 0.05)$ were determined in lesions caused by isolates originating from different hosts (Fig. 6). The most severe decay was observed on quince fruits $(30.83 \mathrm{~mm})$, whereas the smallest lesions were measured on onion bulbs $(10.17$ and $11.00 \mathrm{~mm}$, isolates CLP/7 and CLP/4, respectively). Isolates CLP/3 and CLP/5 were not significantly different from each other, but they were distinguished from isolates CLP/4 and CLP/7, also originating from onion bulbs.
The symptoms reproduced in the pathogenicity assay were quite similar to those observed on the original hosts. Tissue around the wound became discolored, soft, watery, with a clear distinction between diseased and healthy flesh, on all inoculated fruits except orange. The intensity of developed symptoms on the surface of orange fruit was different than on the other inoculated hosts. The lesions observed on orange fruit were small, and the pericarp of the fruit was not soft and watery (Fig. 5C). Five days after
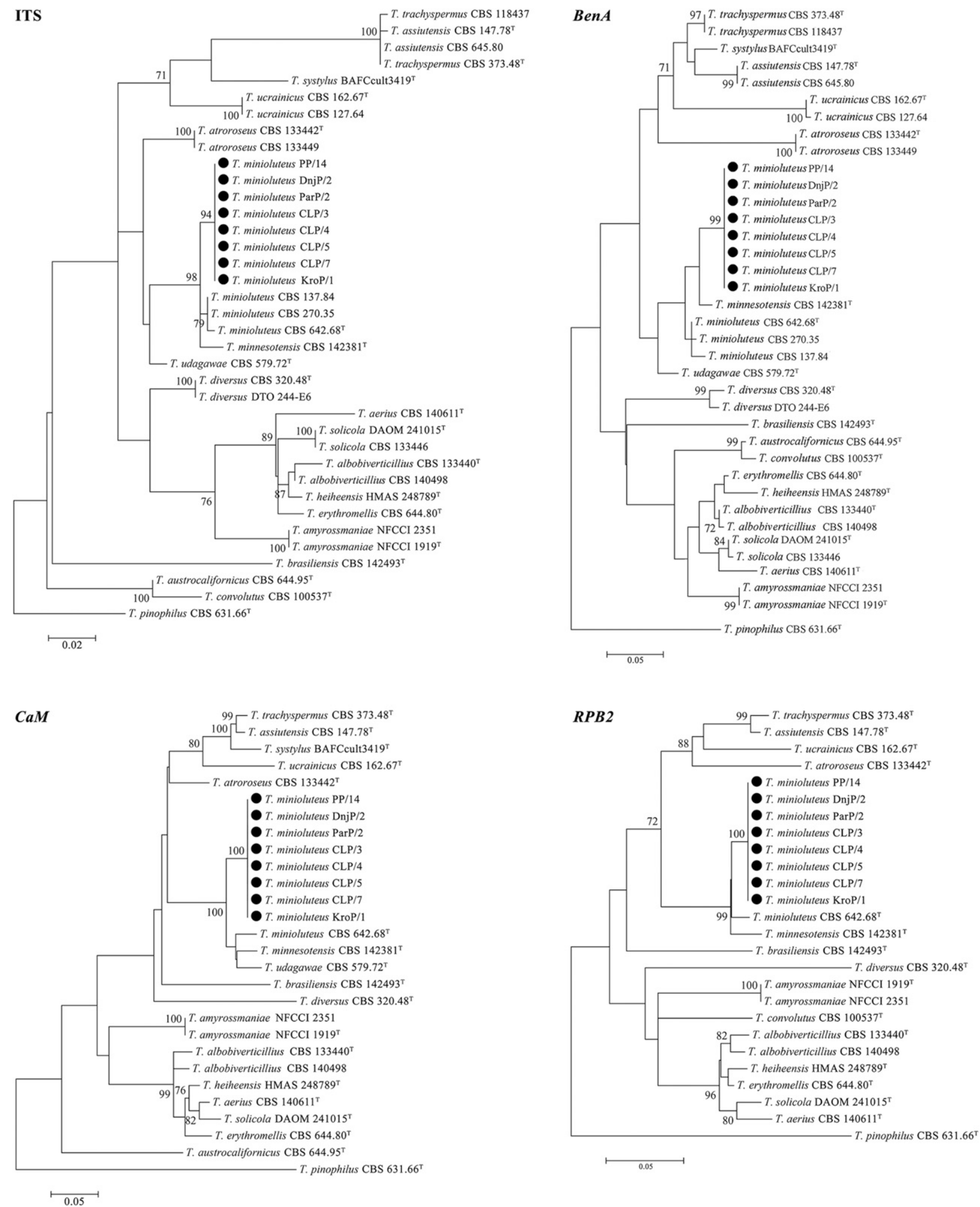

Fig. 3. Maximum likelihood phylogenetic trees of internal transcribed spacer (ITS) region, $\beta$-tubulin (BenA), calmodulin (CaM), and DNA-dependent RNA polymerase II second largest subunit (RPB2) genes of isolates from Talaromyces section Trachyspermi. Sequence of Talaromyces pinophilus (CBS $631.66^{\top}$ ) was used as an outgroup. Bootstrap analysis was performed with 1,000 replicates, and bootstrap values $(>70 \%)$ are shown next to the relevant branches. Talaromyces minioluteus isolates from Serbia are highlighted with black circles. 
inoculation, bright yellow mycelia were observed on quince, tomato, and onion. Ten days after inoculation, moderate sporulation was manifested on the surface of all fruits and bulbs, with dark green spores.

Cross sections (stalk-calyx axis) of the inoculated hosts revealed that in onion bulb fungi were sporulating inside the wound and slowly progressing toward the midpoint of the bulb (Fig. $5 \mathrm{H}$ ); in orange fruit fungi reached the center of the fruit (Fig. 5D); in tomato fruit, the pericarp wall was weakened, deformed, and perforated, and fungi reached the locular cavity (Fig. 5F); and quince fruit was the most severely affected with substantial decay of the pulp into the core (Fig. 5B). Koch's postulates were fulfilled by reisolation $(100 \%)$ from the inoculated quince, tomato, and orange fruits and onion bulbs. Reisolates were not obtained from inoculated potato tubers.

\section{Discussion}

In this study we presented the first results of the 3-year investigation on the presence of T. minioluteus in Serbia on quince, tomato, and orange fruits, onion bulbs, and potato tubers. Based on the literature review, these are the first records of $T$. minioluteus on the listed hosts. Also, this is the first report of this species as a postharvest plant pathogen on quince, tomato, and orange fruits and onion bulbs.

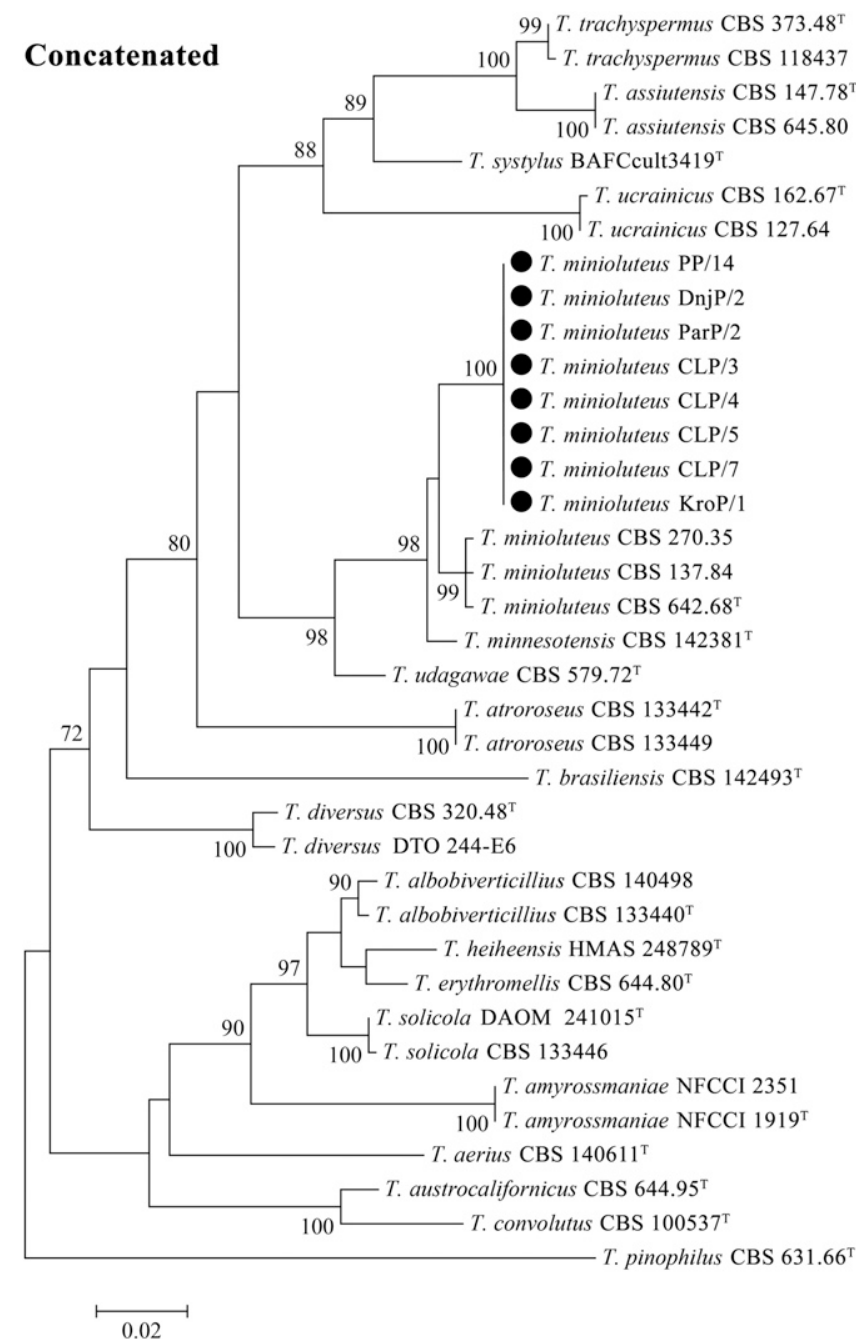

Fig. 4. Maximum likelihood combined phylogenetic tree using internal transcribed spacer region, $\beta$-tubulin, calmodulin, and DNA-dependent RNA polymerase II second largest subunit genes of isolates from Talaromyces section Trachyspermi. Sequence of Talaromyces pinophilus (CBS $631.66^{\top}$ ) was used as an outgroup. Bootstrap analysis was performed with 1,000 replicates, and bootstrap values $(>70 \%)$ are shown next to the relevant branches. The Serbian Talaromyces minioluteus isolates are highlighted with black circles.
Mold symptoms on the various fruits and vegetables used in this study, very similar to those produced by penicillia, were observed during our survey, and their causal agent was identified as T. minioluteus. It can be explained by the fact that many species currently placed in the genus Talaromyces were previously known as Penicillium species. These symptoms included tissue discoloration, brown, usually circular spots, and soft and watery decayed host surface. Later, white and yellow mycelia were observed on diseased tissue, followed by dark green sporulation.

There are several reasons why T. minioluteus has been detected on stored crops at low incidence. T. minioluteus is a species with cosmopolitan distribution but in many studies was isolated at low frequencies compared with other fungi (Hujslová et al. 2010; Magnoli et al. 1998; Nesci et al. 2006; Sage et al. 2004). Low frequencies can be a complicating factor in isolation of this species from stored fruit and vegetables. We can assume that $T$. minioluteus is a weak pathogen, compared with some plant pathogenic penicillia (e.g., $P$. expansum, $P$. digitatum, and $P$. italicum). Weaker growth of this fungus on nutrient-rich artificial media such as CYA, MEA, and YES has also been reported (Yilmaz et al. 2014). As a consequence of these
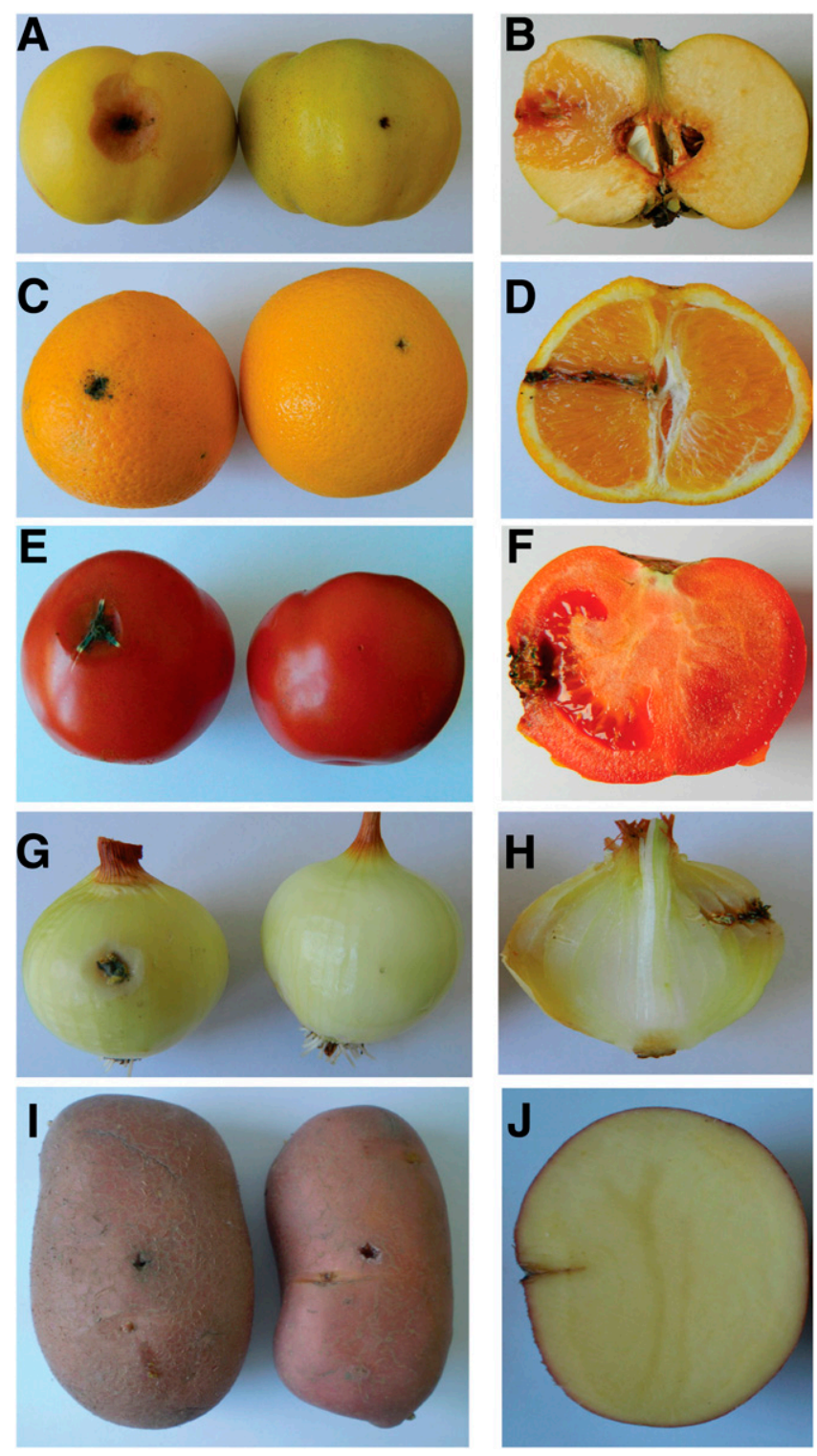

Fig. 5. Pathogenicity on hosts inoculated with corresponding Talaromyces minioluteus isolates after 7 days of incubation: A, quince fruit; C, orange fruit; $\mathbf{E}$, tomato fruit; $\mathbf{G}$, onion bulb; and I, potato tuber. Hosts inoculated with pathogen are to the left and controls to the right. Cross-sections of the inoculated hosts: B, quince fruit; D, orange fruit; $\mathbf{F}$, tomato fruit; $\mathbf{H}$, onion bulb; and $\mathbf{J}$, potato tuber. 
characteristics, other related plant pathogenic species, such as some penicillia, can colonize different plant hosts more rapidly than $T$. minioluteus and can completely cover it. Quintanilla (1985) noticed hyphae of $P$. samsonii $(=T$. minioluteus) on heavily contaminated apple fruit with $P$. expansum after prolonged incubation. Also, infections of the stored crops are often mixed, in which several different species were reported on one host (Borecka 1977; Cole and Wood 1970; Cunningham and Taverner 2007), making the identification of the causal agents based solely on the produced symptoms challenging, if not impossible. It is also difficult to distinguish the symptoms caused by Penicillium from the symptoms induced by Talaromyces species on stored fruits and vegetables. Mukhtar et al. (2019) determined T. funiculosus as causal agent of peach fruit core rot but emphasized that its infection "can be confused with Penicillium postharvest decay." All of the above-specified arguments are the reasons why we obtained and operated with a limited number of $T$. minioluteus isolates in this study.

Morphological characteristics and radial growth measurements on different media of T. minioluteus isolates from this study varied to a small degree in comparison with previous descriptions (Frisvad et al. 1990; Van Reenen-Hoekstra et al. 1990; Visagie 2012; Yilmaz et al. 2014). Out of all tested media, significant difference $(P \leq 0.05)$ among isolates has not been determined only on MEA and CREA. There were no significant differences in culture appearance on the same type of medium between isolates originating from different hosts. Also, there were no significant differences in growth and colony morphology between nonpathogenic isolate $\mathrm{KroP} / 1$ and other tested pathogenic isolates. T. minioluteus belongs to the section Trachyspermi, whose members have restricted growth on CYA, YES, and DG18 and slightly faster growth on MEA (Yilmaz et al. 2014). Growth of our isolates was slightly faster on YES than on MEA. This is different than in Yilmaz et al. (2014) but is in agreement with the findings of Van Reenen-Hoekstra et al. (1990) and Visagie (2012). CREA growth results were consistent with Visagie (2012) and higher than in Yilmaz et al. (2014). The radial growth measurements on DG18 and OA were similar to those reported in the literature (Yilmaz et al. 2014). All of our isolates had more abundant sporulation on all media and slightly faster growth on MEA and YES than isolates from the listed literature sources (Frisvad et al. 1990; Van ReenenHoekstra et al. 1990; Visagie 2012; Yilmaz et al. 2014). Culture appearances of isolates from this work do not differ between each other, but there are some distinctions when compared with the previous descriptions of this species, mostly in colony textures. On CYA, our isolates were velutinous, which is in agreement with descriptions of Visagie (2012). In Yilmaz et al. (2014), T. minioluteus on CYA is floccose and concentrically sulcate. Funiculose texture of tested isolates on MEA is similar to Yilmaz et al. (2014) and different from velutinous cultures of Van Reenen-Hoekstra et al. (1990) and Visagie (2012). On DG18, our cultures were velutinous, which was different than concentrically sulcate colonies in Yilmaz et al. (2014). Our isolates had loosely funiculose texture on OA, whereas in Yilmaz et al. (2014) T. minioluteus was slimy in appearance.

T. minioluteus isolates from this study were tested for growth on CYA at five different temperatures for determination of minimal and maximal temperature growth limits. There was no growth at 5 and $37^{\circ} \mathrm{C}$, which is in agreement with Visagie (2012) and Yilmaz et al. (2014). The strongest growth was observed at the temperature of $30^{\circ} \mathrm{C}$, which is congruent with the results of Visagie (2012). Talaromyces is a mesophilic genus, generally (Houbraken et al. 2014), and our assay confirmed that $T$. minioluteus is a mesophilic species. The growth of our isolates was favored by higher tested temperatures, at 25 and $30^{\circ} \mathrm{C}$. Different temperatures also had an impact on the culture appearance and sporulation of all isolates. Unfortunately, due to a lack of data from other authors about the growth and appearance of the colonies at $15^{\circ} \mathrm{C}$, we are unable to make comparison about this observation. We can only state that the appearance of Serbian T. minioluteus colonies at $30^{\circ} \mathrm{C}$ differed from the ones in Visagie (2012). Our cultures were plane and velutinous at $30^{\circ} \mathrm{C}$, whereas the colonies in Visagie (2012) were slightly raised at the center and floccose. These results can help in anticipation of the possible natural or manmade habitats where T. minioluteus can be detected. It is possible to find it in the markets, where the average temperature is near to the optimal growth temperature. Contrary, it is less likely to encounter T. minioluteus in cold storage rooms, where the temperatures are usually 0 to $5^{\circ} \mathrm{C}$, and this species cannot grow at $5^{\circ} \mathrm{C}$ in vitro, which was confirmed in this and other studies (Visagie 2012; Yilmaz et al. 2014).

Micromorphological features and conidial dimensions of our $T$. minioluteus isolates were in agreement with previous results (Frisvad et al. 1990; Van Reenen-Hoekstra et al. 1990; Visagie 2012; Yilmaz et al. 2014). Our isolates had conidiophores with biverticillate branching type, smooth stipes, acerose phialides, and smooth-walled, ellipsoidal to subglobose conidia. The sexual stage was not observed among Serbian isolates of T. minioluteus, which is consistent with the result of Yilmaz et al. (2014).

Results of the enzyme production tests from this research indicate that our isolates of $T$. minioluteus originating from different hosts showed similar reactions and growth intensities. Lipase and esterase

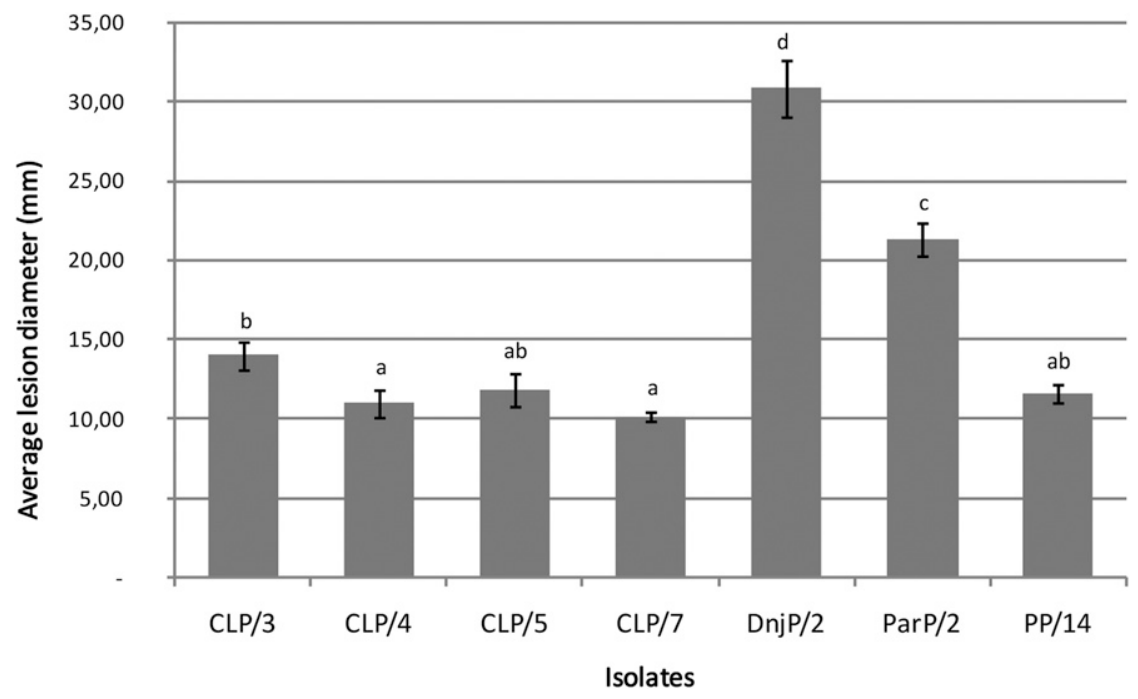

Fig. 6. Pathogenicity of Talaromyces minioluteus isolates on onion bulbs, potato tubers, and quince, tomato, and orange fruits. Numbers with the same letters represent values that are not significantly different according to Tukey's HSD test $(P \leq 0.05)$. Vertical error bars indicate standard deviation of the mean. 
production tests were negative, and the amylase production test was positive. Comparison with previous data are not possible because lipase, esterase, and amylase production have not been reported for T. minioluteus. Fungi produce many enzymes (e.g., lipases, proteases, carbohydrases, and esterases) that have different functions in growth and development, host infection, deterioration of food, and degradation of organic matter (Filtenborg et al. 1996; Hankin and Anagnostakis 1975). More detailed and comprehensive analyses using modern techniques should be performed to examine the enzyme production of T. minioluteus. Previous reports on lipase, esterase, and amylase production by other Talaromyces spp. indicate that these enzymes have a considerable biotechnological potential: from starch bioconversion (Bunni et al. 1989; Xian et al. 2015), use in the food and paper industry (Tuohy et al. 1994), use in the agricultural and food sectors (Crepin et al. 2003; Garcia-Conesa et al. 2004), and utilization in laundry detergents (Romdhane et al. 2010).

Minor differences in various morphological and physiological features of T. minioluteus are reported in this study, compared with literature data (Frisvad et al. 1990; Van Reenen-Hoekstra et al. 1990; Visagie 2012; Yilmaz et al. 2014). Like penicillia (Guerche et al. 2004; Visagie et al. 2014b), T. minioluteus manifests phenotypic plasticity, so variation in micro- and macromorphological characters is expected due to the differences in the environmental factors or loss of the typical features over the years through extensive subculturing. The interpretation of morphological characters often depends on the experience of the researchers, because taxonomy and identification of species from Penicillium and Talaromyces are quite difficult (Dupont et al. 2006; Pitt and Hocking 2009; Pitt and Samson 1990).

Molecular identification and phylogeny based on the sequences of four genetic markers (ITS, BenA, CaM, and RPB2) supported the morphological identification of Serbian $T$. minioluteus isolates. Species-level identification of our isolates as T. minioluteus was easily achieved using each of the four genetic loci. We had very rare ambiguities in BLAST searches of the obtained four genetic marker sequences. Although ITS is the universal genetic barcode for fungi (Schoch et al. 2012), BenA has better resolution in species identification in Penicillium and Talaromyces, and it is proposed as a secondary molecular marker for these taxa (Visagie et al. 2014b; Yilmaz et al. 2014). Yilmaz et al. (2014) stated in their paper that amplification of $R P B 2$ can be very challenging, which we can confirm. We followed their protocol but could not manage to amplify RPB2 using touch-up PCR. Modification of the protocol with a standard PCR cycle and annealing temperature of $60^{\circ} \mathrm{C}$ for primer pair RPB2-5F and RPB2-7CR in our case resulted in clear and satisfying sequences of $R P B 2$. There were no problems in this study with amplification of the calmodulin with CMD5/CMD6 primers, contrary to the experience of Yilmaz et al. (2014). Isolates from this work were grouped together as a single distant branch in each of the four single-gene phylogenetic trees, within the same clade as other reference $T$. minioluteus isolates with high bootstrap support. Phylogenetic tree topologies obtained for all amplified loci were similar to the ones previously published for the section Trachyspermi (Rajeshkumar et al. 2019).

Multilocus phylogenetic analyses were performed with all four sequenced loci, and they confirmed the results of single-gene phylogenetic analyses. In the combined data set, Serbian isolates of $T$. minioluteus were placed jointly in a phylogenetic tree as a single distant branch with high bootstrap support. Reference isolates of $T$. minioluteus and the isolate of T. minnesotensis CBS 142381T were placed in the same clade with our isolates. Topology of the multilocus phylogenetic tree was congruent with the topology of the multigene phylogenetic tree of the section Trachyspermi in the work of Rajeshkumar et al. (2019). Nevertheless, more characterized isolates are necessary for thorough insight in phylogenetic relationships of this species.

Results of our research confirmed that Serbian isolates of T. minioluteus are pathogenic on quince, tomato, and orange fruits and onion bulbs. Pathogenicity of the isolate from potato tuber was not confirmed. Although saprobic, this isolate did not have different phenotypic and molecular characteristics in comparison with the pathogenic isolates from other hosts. A statistically significant difference $(P \leq 0.05)$ has been determined in the degree of necroses on different hosts. The largest lesions were manifested on quince fruits, whereas the smallest lesions were recorded on onion bulbs. Symptoms on artificially inoculated hosts were identical to those from natural infected fruits and vegetables, except on orange fruit, for which visible surface necroses were not observed.

Pathogenicity of $T$. minioluteus $(=P$. minioluteum) on stored fruits and vegetables was only confirmed by Viñas et al. (1993) on apple. In fact, their isolates obtained from apple fruits were among the most resistant to imazalil (Viñas et al. 1993). Palou et al. $(2010,2013)$ isolated T. minioluteus (referred there as P. minioluteum) from pomegranate, among other fungal species. They tested the pathogenicity of $T$. minioluteus on pomegranate, but the outcome was negative. Other Talaromyces spp. as proven postharvest plant pathogens include recent discoveries of T. rugulosus on grapes (Li et al. 2019) and T. funiculosus on peach (Mukhtar et al. 2019). The latter two Talaromyces species were also reported in Serbia, on a fresh-sliced mix of ready-to-use salads (KocićTanackov et al. 2010), but their pathogenicity on the hosts was not examined.

The results of our research provide valuable information and indicate the significance of T. minioluteus. To the best of our knowledge, this is the first report of this species in Serbia. More importantly, these are the first records of $T$. minioluteus as a postharvest plant pathogen on quince, tomato, and orange fruits and onion bulbs. Our future research should be directed at investigating control measures of this pathogen using biological and other alternative control methods.

\section{Acknowledgments}

The authors are thankful to Daniel Mešković for help provided in statistical analyses.

\section{Literature Cited}

Alananbeh, K. M., Boquellah, N., Al Kaff, N., and Al Ahmadi, M. 2017 Evaluation of aerial microbial pollutants in Al-Haram Al-Nabawi during pilgrimage of 2013. Saudi J. Biol. Sci. 24:217-225.

Behr, M., Legay, S., and Evers, D. 2013. Molecular identification of Botrytis cinerea, Penicillium spp. and Cladosporium spp. in Luxembourg. OENO One 47:239-247.

Benjamin, C. R. 1955. Ascocarps of Aspergillus and Penicillium. Mycologia 47: 669-687.

Borecka, H. 1977. Fungi of the genus Penicillium on apples and pears during the storage period. Acta Agrobot. 30:213-227.

Bunni, L., McHale, L., and McHale, A. P. 1989. Production, isolation and partial characterization of an amylase system produced by Talaromyces emersoni CBS 814.70. Enzyme Microb. Technol. 11:370-375.

Camiletti, B. X., Asensio, C. M., Pecci, M. de la P. G., and Lucini, E. I. 2014 Natural control of corn postharvest fungi Aspergillus flavus and Penicillium sp. using essential oils from plants grown in Argentina. J. Food Sci. 79: M2499-M2506.

Chen, A. J., Sun, B. D., Houbraken, J., Frisvad, J. C., Yilmaz, N., Zhou, Y. G., and Samson, R. A. 2016. New Talaromyces species from indoor environments in China. Stud. Mycol. 84:119-144.

Cole, A. L. J., and Wood, R. K. S. 1970. The infection of oranges by Trichoderma viride and mixed infection by Trichoderma viride and Penicillium digitatum. Ann. Appl. Biol. 66:75-82.

Crepin, V. F., Faulds, C. B., and Connerton, I. F. 2003. Production and characterization of the Talaromyces stipitatus feruloyl esterase FAEC in Pichia pastoris: Identification of the nucleophilic serine. Protein Expr. Purif. 29:176-184.

Cunningham, N. M., and Taverner, P. D. 2007. Efficacy of integrated postharvest treatments against mixed inoculations of Penicillium digitatum and Geotrichum citri-aurantii in 'Leng' navel oranges (Citrus sinensis). N. Z. J. Crop Hortic. Sci. 35:187-192.

de Hoog, G. S., and van den Ende, A. H. G. G. 1998. Molecular diagnostics of clinical strains of filamentous Basidiomycetes. Mycoses 41:183-189.

de Souza, G. G., Oliveira, T. S., Takahashi, J. A., Collado, I. G., Macías-Sánchez, A. J., and Hernández-Galán, R. 2012. Biotransformation of clovane derivatives Whole cell fungi mediated domino synthesis of rumphellclovane A. Org. Biomol. Chem. 10:3315-3320.

Dierckx, R. P. 1901. Essai de révision du genre Penicillium Link: Note préliminaire. Ann. la Société Sci. Bruxelles 25:1-88. 
Dupont, J., Dennetière, B., Jacquet, C., and Roquebert, M.-F. 2006. PCR-RFLP of ITS rDNA for the rapid identification of Penicillium subgenus Biverticillium species. Rev. Iberoam. Micol. 23:145-150.

Filtenborg, O., Frisvad, J. C., and Thrane, U. 1996. Moulds in food spoilage. Int. J. Food Microbiol. 33:85-102.

Frisvad, J. C., Samson, R. A., and Stolk, A. C. 1990. Notes on the typification of some species of Penicillium. Persoonia 14:193-202.

Frisvad, J. C., Thrane, U., Samson, R. A., and Pitt, J. I. 2006. Important mycotoxins and the fungi which produce them. Pages 3-31 in: Advances in Food Mycology. A. D. Hocking, J. I. Pitt, R. A. Samson, and U. Thrane, eds. Springer US, Boston, MA

Frisvad, J. C., Yilmaz, N., Thrane, U., Rasmussen, K. B., Houbraken, J., and Samson, R. A. 2013. Talaromyces atroroseus, a new species efficiently producing industrially relevant red pigments. PLoS One 8:e84102.

Garcia-Conesa, M.-T., Crepin, V. F., Goldson, A. J., Williamson, G., Cummings, N. J., Connerton, I. F., Faulds, C. B., and Kroon, P. A. 2004. The feruloyl esterase system of Talaromyces stipitatus: Production of three discrete feruloyl esterases, including a novel enzyme, TsFaeC, with a broad substrate specificity. J. Biotechnol. 108:227-241.

Glass, N. L., and Donaldson, G. C. 1995. Development of primer sets designed for use with the PCR to amplify conserved genes from filamentous ascomycetes. Appl. Environ. Microbiol. 61:1323-1330.

Guerche, L., Garcia, C., Darriet, P., Dubourdieu, D., and Labarère, J. 2004. Characterization of Penicillium species isolated from grape berries by their internal transcribed spacer (ITS1) sequences and by gas chromatography-mass spectrometry analysis of geosmin production. Curr. Microbiol. 48:405-411.

Hankin, L., and Anagnostakis, S. L. 1975. The use of solid media for detection of enzyme production by fungi. Mycologia 67:597-607.

Hong, S.-B., Cho, H.-S., Shin, H.-D., Frisvad, J. C., and Samson, R. A. 2006. Novel Neosartorya species isolated from soil in Korea. Int. J. Syst. Evol. Microbiol. 56:477-486.

Houbraken, J., de Vries, R. P., and Samson, R. A. 2014. Modern taxonomy of biotechnologically important Aspergillus and Penicillium species. Pages 199-249 in: Advances in Applied Microbiology. S. Sariaslani and G. M. Gadd, eds. Vol. 86. Academic Press, London, U.K.

Hujslová, M., Kubátová, A., Chudíčková, M., and Kolařík, M. 2010. Diversity of fungal communities in saline and acidic soils in the Soos National Natural Reserve, Czech Republic. Mycol. Prog. 9:1-15.

Jiang, X.-Z., Yu, Z.-D., Ruan, Y.-M., and Wang, L. 2018. Three new species of Talaromyces sect. Talaromyces discovered from soil in China. Sci. Rep. 8:4932.

Khodaei, A., Arzanlou, M., Babai-Ahari, A., and Houbraken, J. 2016. Five new species of Penicillium and Talaromyces for mycobiota of Iran. Rostaniha 16: 186-199.

Kocić-Tanackov, S., Dimić, G., Lević, J., Pejin, D., Pejin, J., and Jajić, I. 2010. Occurrence of potentially toxigenic mold species in fresh salads of different kinds of ready-for-use vegetables. Acta Period. Technol. 41:33-45.

Kubátová, A. 2000. Neglected Penicillium spp. associated with declining trees. Pages 299-307 in: Integration of Modern Taxonomic Methods for Penicillium and Aspergillus Classification. R. A. Samson and J. I. Pitt, eds. Harwood Academic Publishers, Amsterdam, The Netherlands.

Kumar, S., Stecher, G., and Tamura, K. 2016. MEGA7: Molecular Evolutionary Genetics Analysis Version 7.0 for bigger datasets. Mol. Biol. Evol. 33: 1870-1874.

Labuda, R., Hudec, K., Piecková, E., Mezey, J., Bohovic, R., Mátéová, S., and Lukác, S. S. 2004. Penicillium implicatum causes a destructive rot of pomegranate fruits. Mycopathologia 157:217-223.

Lee, C.-H., Lim, H., Kim, M. K., Cho, Y., Oh, D., Kim, C., and Lim, Y. 2002. Isolation and biological properties of novel cell cycle inhibitor, HY558, isolated from Penicillium minioluteum F558. J. Microbiol. Biotechnol. 12: 470-475.

Li, D., Zhang, X., Gu, X., Zhang, Q., Zhao, L., Zheng, X., and Zhang, H. 2019. The infection of grapes by Talaromyces rugulosus $\mathrm{O} 1$ and the role of cell walldegrading enzymes and ochratoxin $\mathrm{A}$ in the infection. Physiol. Mol. Plant Pathol. 106:263-269.

Liu, X., Chen, C., Zheng, Y., Zhang, M., Tong, Q., Liu, J., Zhou, Q., Wang, J., Luo, Z., Zhu, H., and Zhang, Y. 2018. ( \pm )-Peniorthoesters A and B, two pairs of novel spiro-orthoester en-antiomers with an unusual 1,4,6-trioxaspiro[4.5]decane-7-one unit from Penicillium minioluteum. Front Chem. 6:605.

Liu, Y. J., Whelen, S., and Hall, B. D. 1999. Phylogenetic relationships among ascomycetes: Evidence from an RNA polymerase II subunit. Mol. Biol. Evol. 16:1799-1808

Magnoli, C., Dalcero, A. M., Chiacchiera, S. M., Miazzo, R., and Saenz, M. A. 1998. Enumeration and identification of Aspergillus group and Penicillium species in poultry feeds from Argentina. Mycopathologia 142:27-32.

Masclaux, F., Guého, E., de Hoog, G. S., and Christen, R. 1995. Phylogenetic relationships of human-pathogenic Cladosporium (Xylohypha) species inferred from partial LS rRNA sequences. J. Med. Vet. Mycol. 33:327-338.

McGee, P. A., Markovina, A.-L., Jeong, G. C. E., and Cooper, E. D. 2006. Trichocomaceae in bark survive high temperatures and fire. FEMS Microbiol. Ecol. 56:365-371.

Mukhtar, I., Quan, X., Chou, T., Huang, Q., Yan, J., Chen, B., Jiang, S., Liu, F., Wen, Z., and Xie, B. 2019. First report of Talaromyces funiculosus causing fruit core rot of peach (Prunus persica) in China. Plant Dis. 103:2124.
Nesci, A., Barros, G., Castillo, C., and Etcheverry, M. 2006. Soil fungal population in preharvest maize ecosystem in different tillage practices in Argentina. Soil Tillage Res. 91:143-149.

Ngokpol, S., Suwakulsiri, W., Sureram, S., Lirdprapamongkol, K., Aree, T., Wiyakrutta, S., Mahidol, C., Ruchirawat, S., and Kittakoop, P. 2015. Drimane sesquiterpene-conjugated amino acids from a marine isolate of the fungus Talaromyces minioluteus (Penicillium minioluteum). Mar. Drugs 13:3567-3580.

Okada, H., Kamiya, S., Shiina, Y., Suwa, H., Nagashima, M., Nakajima, S. Shimokawa, H., Sugiyama, E., Kondo, H., Kojiri, K., and Suda, H. 1998. BE-31405, a new antifungal antibiotic produced by Penicillium minioluteum I. Description of producing organism, fermentation, isolation, physicochemical and biological properties. J. Antibiot. (Tokyo) 51:1081-1086.

Palou, L., Guardado, A., and Montesinos-Herrero, C. 2010. First report of Penicillium spp. and Pilidiella granati causing postharvest fruit rot of pomegranate in Spain. New Dis. Rep. 22:21-22.

Palou, L., Taberner, V., Guardado, A., Del Río, M. Á., and Montesinos-Herrero, C. 2013. Incidence and etiology of postharvest fungal diseases of pomegranate (Punica granatum cv. Mollar de Elche) in Spain. Phytopathol. Mediterr. 52: 478-489.

Paterson, R. R., and Bridge, P. D. 1994. Biochemical Techniques for Filamentous Fungi. CABI, Wallingford, U.K

Peterson, S. W., and Jurjević, Ž. 2017. New species of Talaromyces isolated from maize, indoor air, and other substrates. Mycologia 109:537-556.

Pianzzola, M. J., Moscatelli, M., and Vero, S. 2004. Characterization of Penicillium isolates associated with blue mold on apple in Uruguay. Plant Dis. 88:23-28.

Pitt, J. I. 1979. The Genus Penicillium and Its Teleomorphic States Eupenicillium and Talaromyces. Academic Press, London, U.K.

Pitt, J. I., and Hocking, A. 2009. Fungi and Food Spoilage, 3rd Ed. Springer, New York, NY.

Pitt, J. I., and Samson, R. A. 1990. Approaches to Penicillium and Aspergillus systematics. Stud. Mycol. 32:77-90.

Quintanilla, J. A. 1985. Three new species of Penicillium belonging to Subgenus Biverticillium Dierckx, isolated from different substrates. Mycopathologia 91: 69-78.

Rajeshkumar, K. C., Yilmaz, N., Marathe, S. D., and Seifert, K. A. 2019. Morphology and multigene phylogeny of Talaromyces amyrossmaniae, a new synnematous species belonging to the section Trachyspermi from India. MycoKeys 45:41-56.

Ramírez, C., and Martínez, A. T. 1981. Four new species of Penicillium isolated from different substrata. Mycopathologia 74:163-171.

Raper, C., and Thom, K. B. 1949. Manual of the Penicillia, 1st Ed. Williams \& Wilkins, Baltimore, MD

Romdhane, I. B.-B., Fendri, A., Gargouri, Y., Gargouri, A., and Belghith, H. 2010 A novel thermoactive and alkaline lipase from Talaromyces thermophilus fungus for use in laundry detergents. Biochem. Eng. J. 53:112-120.

Sage, L., Garon, D., and Seigle-Murandi, F. 2004. Fungal microflora and ochratoxin A risk in French vineyards. J. Agric. Food Chem. 52:5764-5768.

Samson, R. A., Yilmaz, N., Houbraken, J., Spierenburg, H., Seifert, K. A. Peterson, S. W., Varga, J., and Frisvad, J. C. 2011. Phylogeny and nomenclature of the genus Talaromyces and taxa accommodated in Penicillium subgenus Biverticillium. Stud. Mycol. 70:159-183.

Schoch, C. L., Seifert, K. A., Huhndorf, S., Robert, V., Spouge, J. L., Levesque, C. A., and Chen, W. 2012. Nuclear ribosomal internal transcribed spacer (ITS) region as a universal DNA barcode marker for fungi. Proc. Natl. Acad. Sci. U.S.A. 109:6241-6246

Seifert, K. A., and Frisvad, J. C. 2000. Penicillium on solid wood products. Pages 285-298 in: Integration of Modern Taxonomic Methods for Penicillium and Aspergillus Classification. R. A. Samson and J. I. Pitt, eds. Harwood Academic Publishers, Amsterdam, The Netherlands.

Sudha, Gupta, C., and Aggarwal, S. 2017. Optimization and extraction of extra and intracellular color from Penicillium minioluteum for application on protein fibers. Fibers Polym. 18:741-748.

Tang, H.-Y., Zhang, Q., Gao, Y.-Q., Zhang, A.-L., and Gao, J.-M. 2015. Miniolins $\mathrm{A}-\mathrm{C}$, novel isomeric furanones induced by epigenetic manipulation of Penicillium minioluteum. RSC Advances 5:2185-2190.

Thompson, J. D., Higgins, D. G., and Gibson, T. J. 1994. CLUSTAL W: Improving the sensitivity of progressive multiple sequence alignment through sequence weighting, position-specific gap penalties and weight matrix choice. Nucleic Acids Res. 22:4673-4680.

Tosi, S., Casado, B., Gerdol, R., and Caretta, G. 2002. Fungi isolated from Antarctic mosses. Polar Biol. 25:262-268.

Tuohy, M. G., Laffey, C. D., and Coughlan, M. P. 1994. Characterization of the individual components of the xylanolytic enzyme system of Talaromyces emersonii. Bioresour. Technol. 50:37-42.

Van Reenen-Hoekstra, E. S., Frisvad, J. C., Samson, R. A., and Stolk, A. C. 1990. The Penicillium funiculosum complex-Well defined species and problematic taxa. Pages 173-192 in: Modern Concepts in Penicillium and Aspergillus Classification. R. A. Samson and J. I. Pitt, eds. Springer US, Boston, MA

Viñas, I., Vallverdu, N., Monllao, S., Usall, J., and Sanchis, V. 1993. Imazalil resistant Penicillium isolates from Spanish apple packinghouses. Mycopathologia $123: 27-33$ 
Visagie, C. M. 2012. The polyphasic taxonomy of Penicillium and Talaromyces spp. isolated from the diverse Fynbos biome. Ph.D. thesis. Stellenbosch University, Stellenbosch, South Africa.

Visagie, C. M., Hirooka, Y., Tanney, J. B., Whitfield, E., Mwange, K., Meijer, M., Amend, A. S., Seifert, K. A., and Samson, R. A. 2014a. Aspergillus, Penicillium and Talaromyces isolated from house dust samples collected around the world. Stud. Mycol. 78:63-139.

Visagie, C. M., Houbraken, J., Frisvad, J. C., Hong, S.-B., Klaassen, C. H. W., Perrone, G., Seifert, K. A., Varga, J., Yaguchi, T., and Samson, R. A. 2014b. Identification and nomenclature of the genus Penicillium. Stud. Mycol. 78:343-371.
Williams, A. P. 1990. Penicillium and Aspergillus in the food microbiology laboratory. Pages 67-71 in: Modern Concepts in Penicillium and Aspergillus Classification. R. A. Samson and J. I. Pitt, eds. Springer US, Boston, MA.

Xian, L., Wang, F., Luo, X., Feng, Y.-L., and Feng, J.-X. 2015. Purification and characterization of a highly efficient calcium-independent $\alpha$-amylase from Talaromyces pinophilus 1-95. PLoS One 10:e121531.

Yilmaz, N., Visagie, C. M., Houbraken, J., Frisvad, J. C., and Samson, R. A. 2014. Polyphasic taxonomy of the genus Talaromyces. Stud. Mycol. 78: $175-341$. 